\title{
Relações entre taxa real de câmbio, exportações e crescimento econômico
}

\author{
Luciano Nakabashi*
}

RESUMO: Algumas evidências e teorias apontam para a existência de uma relação entre crescimento econômico e saldo da balança comercial e da conta corrente. Ou seja, de acordo com essa abordagem é fundamental um bom desempenho do setor exportador de forma a manter uma conta corrente equilibrada para que um determinado país consiga manter um bom nível de investimentos e de crescimento de forma sustentável. O presente estudo realiza uma revisão da literatura que relaciona as relações macroeconômicas apresentadas acima, além de apresentar alguns resultados de estudos empíricos.

Palavras-chave: Exportações. Taxa de câmbio real. Crescimento econômico.

\section{INTRODUÇÃO}

Existe uma relação enfatizada por alguns economistas, há algum tempo, entre crescimento econômico e o saldo da conta de transações correntes. Ou seja, de acordo com essa abordagem, é fundamental um bom desempenho do setor exportador de forma a manter uma conta corrente equilibrada para que um determinado país consiga manter elevados níveis de investimentos e de crescimento de forma sustentável.

O desempenho da balança comercial e da conta de transações correntes pode ser relevante no montante de investimentos e no crescimento de um determinado país, pois caso ocorra uma piora na balança comercial as consequências são efeitos contracionistas sobre os setores diretamente afetados pelo aumento das importações e/ou queda das exportações. Outro ponto importante é que nenhum país pode crescer mais rápido que a taxa de crescimento com equilíbrio na $\mathrm{BP}$, pelo menos no longo prazo, pois um déficit crescente na conta de transações correntes financiado através da conta capital aumentaria o risco de desvalorizações cambiais até o ponto em que não valeria mais a pena investir em tal região ou país.

* Coordenador do boletim de Economia \& Tecnologia. Pesquisador do CNPQ. É professor adjunto do Departamento de Economia da UFPR.Endereço eletrônico: luciano.nakabashi@gmail.com. 
Desse modo, ele teria que se ajustar à nova situação através de medidas recessivas espontâneas ou forçadas. Os ajustes forçados seriam através de crises de confiança com fugas de capital, grande depreciação da moeda doméstica, com uma consequente fragilidade financeira do setor público e privado, além da redução no nível de investimentos. Finalmente, um déficit crescente na conta de transações correntes levaria o país ou região a praticar taxas de juros mais elevadas para atrair fluxos de capital, estimulando a valorização financeira do capital em prejuízo do investimento produtivo e do crescimento real da economia. Portanto, um bom desempenho do setor exportador de forma a manter em equilíbrio o saldo da conta de transações correntes seria essencial para a manutenção de um bom desempenho econômico de forma sustentada.

Além de relaxar a restrição do setor externo, altas taxas de crescimento das exportações dinamizam a economia pela possibilidade que se abre na produção de bens mais intensivos em tecnologia, ou seja, devido ao processo de descolamento entre o consumo doméstico e a produção doméstica, além do preço das exportações ser inelástico em relação à quantidade produzida, como argumentado por Eichengreen (2008). Adicionalmente, o crescimento sustentável das exportações, com ganhos de participação desse setor no PIB, estimula o crescimento econômico porque esse setor possui maior capacidade de absorver tecnologia do resto do mundo e de aproveitar os ganhos através do learning by doing quando se compara com os demais setores da economia (EICHENGREEN, 2008).

Considerando as relações macroeconômicas acima citadas, o presente estudo visa realizar uma revisão da literatura que relaciona as variáveis câmbio, exportações e crescimento, além de apresentar alguns resultados de estudos empíricos. Além da presente introdução, apresentamos uma revisão da bibliografia na seção 2 , seguida pela apresentação de resultados de alguns estudos empíricos. Por fim, concluimos o estudo.

\section{REVISÃO BIBLIOGRÁFICA}

\subsection{CRESCIMENTO ECONÔMICO E DESEMPENHO DA BALANÇA COMERCIAL}

Primeiramente, consideramos a relação entre crescimento econômico e restrição externa. A base teórica está em um modelo pós-keynesiano desenvolvido por Thirlwall (1979) que enfatiza o papel da demanda externa sobre o crescimento. Nesse modelo, as elasticidades renda das importações e das exportações são elementos chave para um bom desempenho econômico de longo prazo. 
Posteriormente, o modelo original de 1979 foi estendido por Thirlwall e Hussain (1982) para incluir fluxos de capital. Moreno-Brid (1998) trouxe avanços adicionais ao introduzir uma restrição que limita o crescimento do déficit em conta corrente como proporção da renda doméstica. De acordo com este modelo, o país tem que manter certa proporção entre déficit externo e nível de renda de modo a obter um crescimento sustentável no longo prazo. McCombie e Thirlwall (1997) fazem avanços similares no sentido de introduzir uma restrição para que a razão entre os déficits comerciais e a renda seja constante.

No entanto, Barbosa Filho (2002) mostra que esta condição não é suficiente para impedir uma elevação da dívida externa em níveis que não sejam sustentáveis, pois mesmo com uma razão constante entre déficit em conta corrente e renda doméstica, a trajetória do crescimento da dívida pode chegar a níveis que geram crises de confiança de modo a tornar insustentável o padrão atual de crescimento. $\mathrm{O}$ autor inclui na análise, de forma explícita, o pagamento de juros e a dinâmica da dívida externa para contornar o problema.

Todas estas versões do modelo original de Thirlwall (1979) preservam sua ideia central, ou seja, que a taxa de crescimento do produto no longo prazo precisa respeitar a restrição do balanço de pagamentos. Em algum momento da trajetória de crescimento, a restrição externa se fará sentir, impondo ajustes ou limitando a própria taxa de crescimento.

De fato, existem boas razões para que se acredite na validade da suposição de que o desempenho da balança comercial, ou seja, das importações e exportações, tenham um papel crucial no crescimento de uma determinada economia por, pelo menos, três motivos: 1) os efeitos contracionistas sobre os setores diretamente afetados pelo aumento das importações e/ou queda das exportações; 2) nenhum país pode crescer mais rápido que a taxa de crescimento com equilíbrio na BP, pelo menos no longo prazo, pois um déficit crescente na conta corrente financiado através da conta capital aumentaria o risco de desvalorizações cambiais até o ponto em que não valeria mais a pena investir em tal região ou país e, desse modo, ele teria que se ajustar à nova situação através de medidas recessivas espontâneas ou forçadas; e 3) um déficit crescente em conta corrente levaria o país ou região a praticar taxas de juros mais elevadas para atrair fluxos de capital, estimulando a valorização financeira do capital em prejuízo do crescimento real da economia.

A essência do modelo é que o país deve manter o saldo da BP em equilíbrio, no longo prazo, pois um país não pode se endividar continuamente sem nunca ter que pagar sua dívida. Caso o país tenha um déficit persistente na conta de transações correntes, chegará um 
momento em que ele deverá reduzir seu crescimento, elevar o montante de bens e serviços exportados e/ou reduzir a elasticidade renda das importações para inverter o déficit.

Como uma elevada taxa de crescimento é seguida por incrementos no montante das importações de forma quase proporcional, para que um determinado país mantenha um crescimento econômico de forma sustentável é necessário que o seu setor exportador obtenha um bom desempenho de forma a manter o saldo da conta de transações correntes em equilíbrio.

Em outras palavras, de acordo com a teoria apresentada, para que determinado país possa almejar elevadas taxas de crescimento por um razoável período de tempo, é indispensável manter as contas externas em equilíbrio para que elas não se tornem uma restrição ao próprio crescimento. Caso o crescimento econômico não seja acompanhado por um bom desempenho do setor exportador, o país entrará em crises de balanço de pagamentos com fortes impactos no nível de investimento e no crescimento da renda.

Essa dependência das exportações é ainda mais relevante para os países em desenvolvimento visto que a conta de serviços dos mesmos permanece negativa na maior parte do tempo. Isso ocorre devido às entradas anteriores de capitais que pressionam a conta de serviços pela remessa de lucros e pagamento de juros aos investidores externos. Isso é notadamente verdade no caso da economia brasileira, como veremos posteriormente.

\subsection{RELAÇÃO ENTRE TAXA DE CÂMBIO REAL, EXPORTAÇÕES E CRESCIMENTO ECONÔMICO}

\subsubsection{Crescimento e exportações}

A relação entre desempenho das exportações e crescimento pode ser percebida pelo modelo de Thirlwall mencionado na seção anterior. No entanto, além de relaxar a restrição externa, o crescimento das exportações favorece o crescimento econômico através de outras vias.

A primeira delas seria o descolamento entre o consumo doméstico e a produção doméstica, segundo Eichengreen (2008). Esse processo de descolamento possibilita uma elevação da produção de bens de maior conteúdo tecnológico com destino aos países desenvolvidos. Isto ocorre porque a demanda interna de países em desenvolvimento tende a ser direcionada, principalmente, para bens de baixo valor agregado e reduzido conteúdo tecnológico como consequência do baixo nível de renda média da população.

80 
A segunda via, também destacada por Eichengreen (2008), é que o aumento da oferta de bens para a economia mundial não tem efeitos significativos nos preços devido ao tamanho do mercado mundial em relação à economia doméstica. Ou seja, um crescimento dos bens exportados não teria impactos negativos sobre seus respectivos níveis de preço.

Uma terceira e mais importante de todas as vias seria o estímulo ao crescimento decorrente do bom desempenho do setor exportador porque este possui maiores ganhos de produtividade proveniente do processo de absorção de tecnologia do resto do mundo, além do seu maior potencial de learning by doing quando se compara com os demais setores da economia (EICHENGREEN, 2008).

\subsubsection{Câmbio e exportações}

Se o desempenho das exportações é tão importante para explicar a taxa de crescimento de uma economia, deveríamos buscar quais os elementos que determinam seu comportamento. Uma das variáveis mais relevantes é a taxa de câmbio real. Por isso, essa variável está no centro das discussões em qualquer modelo que trate do crescimento puxado ou dependente das exportações, como é o caso da lei de Thirlwall.

Considerando que a condição de Marshall-Lerner ${ }^{1}$ seja satisfeita, depreciações reais da taxa de câmbio levam a uma melhora no desempenho das exportações líquidas. Vários estudos empíricos mostram que essa condição é satisfeita. Podemos citar alguns estudos que mostram essa relação como Krugman e Baldwin (1987) para a economia norte-americana, Gupta-Kapoor e Ramakrishnan (1999) para a economia japonesa, Boyd, Caporale e Smith (2001) para os países da OCDE, Onafowora (2003) para os países do Leste Asiático, além de Gomes e Lourenço (2005) para a economia brasileira. Desse modo, as evidências empíricas sugerem que existe uma relação relevante entre depreciação real da taxa de câmbio e melhora nas exportações líquidas.

\footnotetext{
${ }^{1}$ Se a condição de Marshall-Lerner é satisfeita, isso indica que uma depreciação real da moeda doméstica conduz a uma elevação nas exportações líquidas, ou seja, melhora o saldo da balança comercial tanto pelo estímulo às exportações quanto pela retração das importações. No entanto, essa condição não é satisfeita no curtíssimo prazo, pois o efeito sobre os preços acaba sendo maior do que sobre as quantidades. Ou seja, após uma depreciação cambial real, as exportações líquidas tendem a piorar para depois apresentarem uma melhora. Esse fenômeno é conhecido como Curva J. Veja, por exemplo, Boyd, Caporale e Smith (2001).
} 


\subsubsection{Câmbio e crescimento}

Esse tipo de estímulo às exportações (depreciação cambial) é ainda mais importante em países em desenvolvimento, de acordo com Rodrick (2008). O autor ressalta que o setor de bens comercializáveis sofre relativamente mais com o fraco arcabouço institucional e com as falhas de mercado existentes nesse grupo de países. Assim, uma maneira de amenizar esses dois tipos de problemas seria a adoção de uma política de depreciação da taxa de câmbio real de forma a estimular o investimento no setor de bens comercializáveis.

Outro ponto relevante é que uma taxa real de câmbio depreciada ou desvalorizada pode ser utilizada como um incentivo para a alocação de recursos para o setor de manufatura ou para a indústria em detrimento dos bens não comercializáveis e das commodities, de acordo com Eichengreen (2008).

Adicionalmente, nos países em desenvolvimento, o setor de commodities é intensivo em recursos abundantes nesse grupo de países (terra e trabalho), além deste ser estimulado pela demanda externa em vários momentos. Desse modo, o setor de commodities é "naturalmente" competitivo nesse grupo de países. Por outro lado, o setor de bens manufaturados não o é, em geral, devido à dotação de fatores, às instituições em processo de consolidação, e às falhas de mercado. Portanto, uma depreciação da taxa real de câmbio favorece o setor de bens comercializáveis e, principalmente, o setor de bens manufaturados.

Assim, pelos argumentos apontados acima, a taxa de câmbio é um preço chave não só na determinação do desempenho das exportações, como também para o estímulo das exportações de produtos manufaturados.

Outro ponto relevante da estratégia de depreciação cambial é que ela eleva o nível de poupança e investimentos de forma a estimular o processo de acumulação de capital, de acordo com Bresser-Pereira (2004). Segundo o autor, uma taxa de câmbio competitiva mantém os salários reais em níveis baixos, assim como o consumo que é uma função da renda. Por outro lado, o câmbio depreciado provoca oportunidades de obtenção de lucros para as empresas do setor exportador, o que acaba promovendo uma elevação nos investimentos.

\section{ALGUMAS EVIDÊNCIAS EMPÍRICAS}

De fato, alguns estudos apontam que o processo de depreciação ou apreciação cambial foram variáveis chave no sucesso ou insucesso econômico de alguns países. Por exemplo, Sachs (1985) mostram que a estratégia de depreciação cambial adotada pelos países 
do Leste Asiático foi essencial para explicar o melhor desempenho destes na crise dos anos 80 quando se compara com o desempenho dos países da América Latina.

Segundo Sachs (1985), enquanto os países da América Latina estavam buscando um crescimento econômico via substituição de importações, antes da grande mudança no cenário internacional que provocou a crise da dívida nos mesmos, os países asiáticos vinham de um processo de crescimento liderado pelas exportações com a manutenção de taxas reais de câmbio depreciadas.

Carvalho e Lima (2009) também mostram a importância do câmbio real para explicar a lenta recuperação da economia brasileira da crise dos anos 80. As evidências desse estudo apoiam a ideia de que a valorização do câmbio real entre 1982 e 1993 fez com que a taxa de crescimento da economia brasileira com equilíbrio do balanço de pagamentos fosse ainda mais baixa.

Ao estender o período de análise do estudo realizado por Sachs (1985), Gala (2007) apresenta evidências de que a taxa de câmbio foi essencial para explicar o diferencial de crescimento entre os dois grupos de países acima citados, no período 1970-2000. O autor mostra que, nesse período, ocorreram consideravelmente mais ciclos de apreciação da taxa de câmbio nos últimos em relação aos primeiros. Em suas palavras:

Estendendo a análise de Sachs (1985), a história aqui apresentada parece se resumir a uma tendência recorrente de ciclos de sobrevalorização na América Latina e subvalorização na Ásia, especialmente após o final dos anos 1970. Enquanto os primeiros passaram por vários ciclos de sobrevalorização cambial, com o já conhecido populismo econômico dos anos 1970 e 1980 e com os planos de estabilização dos anos 1990, os países asiáticos concentraram-se na sua estratégia de "export-led growth" com estímulo permanente ao setor exportador, evitando fortes apreciações cambiais... Nesse sentido, a estratégia de industrialização com promoção de exportações (EPI) do Leste e Sudeste Asiático provou-se muito mais eficaz do que a estratégia de substituição de importações latino-americana (ISI). (GALA, 2007, p. 86).

Utilizando uma série de 184 países para o período 1950-2004, Rodrick (2008) apresenta evidências de que a manutenção da taxa de câmbio real em níveis competitivos é uma variável chave para explicar uma maior taxa de crescimento das economias em desenvolvimento. Ainda de acordo com os resultados, o mesmo não seria válido para o grupo de países desenvolvidos. Esses resultados dão suporte ao argumento do autor de que o setor de bens comercializáveis dos países em desenvolvimento sofre proporcionalmente mais com a fragilidade das instituições e com as falhas de mercado em relação ao setor de bens não comercializáveis. 
Em um estudo para analisar se o processo de fluxo de capitais de países em desenvolvimento para países desenvolvidos prejudicaram seus respectivos processos de crescimento, Prasad, Rajan e Subramanian (2007) encontram que aqueles países que mantiveram um superávit na conta de transações correntes também experimentaram taxas mais altas de crescimento. Ou seja, a estratégia de crescimento sem grande ou nenhuma dependência de poupança externa foi a que apresentou maior sucesso.

Os autores consideraram, na análise, o período 1970-2004 para 59 países em desenvolvimento $^{2}$, além de China e Índia. Dividindo os países em grupos de acordo com o crescimento econômico, eles encontraram que os países que mais cresceram foram aqueles que obtiveram menores entradas líquidas de capitais. $O$ país que apresentou maior crescimento foi um exportador líquido de capital, sendo este país a China. Desse modo, de acordo com os resultados apresentados pelos autores, os países que apostaram em uma estratégia de crescimento puxado pelas exportações foram aqueles que apresentaram maior taxa de crescimento no período. Isso ocorreu, parcialmente, porque aqueles países que basearam suas estratégias de crescimento em poupança externa apresentaram longos períodos de apreciação da taxa de câmbio real.

De uma forma geral, os estudos empíricos apontam para a importância de uma taxa de câmbio competitiva para estimular as exportações de uma economia. Adicionalmente, um bom desempenho do setor exportador acaba tendo impactos positivos sobre a taxa de crescimento econômico pelos motivos apontados anteriormente, pelo menos para países em desenvolvimento.

Cabe ressaltar, ainda, que um crescimento com dependência de poupança externa, ou seja, que atraia uma grande quantidade de fluxos de capitais, além de causar problemas de apreciação cambial, leva a um fluxo de pagamentos de juros e remessa de lucros ao exterior via balança de serviços em períodos futuros de forma a reduzir a taxa de crescimento com equilíbrio nas contas externas, de acordo com o modelo de Thirlwall e com as evidências apresentadas por Ferreira e Canuto (2003) para o Brasil.

\section{CONCLUSÕES}

Concluindo, de acordo com os argumentos apresentados, uma taxa de câmbio competitiva estimula as exportações líquidas de forma a relaxar a restrição externa, além de

\footnotetext{
${ }^{2} \mathrm{Ou}$ não industriais, sendo este o termo utilizado pelos autores.
} 
proporcionar que uma determinada economia alcance taxas mais elevadas de crescimento econômico. Adicionalmente, a competitividade da taxa de câmbio incentiva a alocação de recursos para o setor de manufatura em detrimento dos bens não comercializáveis e das commodities, estimula o investimento em setores mais dinâmicos e compensa, parcialmente, o fraco arcabouço institucional e as falhas de mercado existentes em maior quantidade nos países em desenvolvimento.

O bom desempenho do setor exportador ainda age no sentido de possibilitar uma elevação da produção de bens de maior conteúdo tecnológico, não gera impactos significativos em seus preços e estimula ganhos de produtividade proveniente do processo de absorção de tecnologia do resto do mundo e do processo de learning by doing quando se compara com os demais setores da economia.

\section{REFERÊNCIAS}

BARBOSA FILHO, N.H. The Balance of Payments Constraint: From Balanced Trade to Sustainable Debt. Center for Economic Policy Analysis Working Paper, v.6, p.1-24, 2002.

BOYD, D.; CAPORALE, G.M.; SMITH. R. Real exchange rate effects on the balance of trade: cointegration and the Marshall-Lerner condition. International Journal of Finance and Economics, v.6, p.187-200, 2001.

BRESSER PEREIRA, L.C. Exchange rate: fix, float, or manage it?. Fundação Getúlio Vargas, v.135: p.1-12, 2004. Discussão.

BRESSER PEREIRA, L.C.; NAKANO, Y. Crescimento Econômico com Poupança Externa. Revista de Economia Política, v.23, p.3-27, 2003.

CARVALHO,V.R.S.; LIMA,G.T. Estrutura produtiva, restrição externa e crescimento econômico: a experiência brasileira. Economia e Sociedade, v.18, p.31-60, 2009.

EICHENGREEN, B. The Real Exchange Rate and Economic Growth. Comission on Growth and Development Working Paper No, v.4, 2008.

FERREIRA, A.; CANUTO, O.Thirlwall's Law and foreign capital in Brazil. Momento Econômico, v.125, p.18-29, 2003.

GALA, P. Dois padrões de política cambial: América Latina e Sudeste Asiático. Economia e Sociedade, v.16 (01) p.65-91, 2007.

GOMES, F.A.R.; LOURENÇO,S.P. Can real exchange rate devaluation improve the trade balance? The 1990-1998 Brazilian case. Applied Economics Letters, v.12 (9), p.525-528, 2005.

GUPTA KAPOOR, A.; RAMAKRISHNAN, U. Is there a J-Curve? A new estimation for Japan. International Economic Journal, v.13, p.71-79, 1999.

KRUGMAN, P.; BALDWIN, R.E. The Persistence of the U.S. Trade Deficit. Brookings Papers on Economic Activity, v.1, p.1-43, 1987. 
MCCOMBIE, J.S.L., THIRLWALL, A.P. Economic Growth and the Balance of Payments Revisited. In: ARESTIS, P., PALMA, G., SAWYER,M.(eds). Markets, Unemployment and Economic Policy: Essays in Honour of Geoffrey Harcou, v.2, London, p.498-511, 1997.

MORENO BRID, J.C. On Capital Flows and the Balance of Payments-Constraint Growth Model. Journal of Post Keynesian Economics, v.21, p.283-298, 1998.

ONAFOWORA, O. Exchange rate and trade balance in East Asia: is there a J-Curve? Economics Bulletin, v.05, p.1-13, 2003.

PRASAD, E.; RAJAN, R.; SUBRAMANIAN, A. Foreign capital and economic growth. Discussion Paper Series, IZA DP, 3186, 2007.

RODRIK, D. The Real Exchange Rate and Economic Growth. Brookings Papers on Economic Activity, Conference Draft, 2008.

SACHS, J. External debt and macroeconomic performance in Latin America and East Asia. Brookings Papers on Economic Activity, v.2, p.523-573, 1985.

THIRLWALL, A.P. The Balance of Payments Constraint as a Explanation of International Growth Rate Differences. Banca Nazionale del Lavoro Quarterly Review, v.128, 1979.

THIRLWALL, A.P., HUSSAIN, M.N.. The Balance of Payments Constraint, Capital Flows and Growth Rate Differences Between Developing Countries, Oxford Economic Papers, v.10, p.498-509, 1982. 